Jean Philippe Tonneau

Doutor em Geografia, CIRAD. E-mail: tonneau@cirad.fr

Luis Henrique Cunha

Doutor em Desenvolvimento Sócio-Ambiental, PPGCS/UFCG.

E-mail:luishcunha@uol.com.br

\title{
PESQUISAS EM DESENVOLVIMENTO TERRITORIAL NO SEMI-ÁRIDO
}

\section{RESUMO}

O artigo tem como objetivo aprofundar a discussão sobre o conceito de território e suas relações com o desenvolvimento local sustentável no semi-árido nordestino. Nesta perspectiva, o artigo tenta responder a perguntas como: O que são territórios e por que devem ser privilegiados enquanto orientadores de programas de pesquisa e de políticas públicas? O que significa desenvolvimento territorial e em que este conceito se diferencia da noção de desenvolvimento local? Como a referência a este enfoque pode ajudar a resolver os graves problemas da sociedade brasileira, levando em conta inclusive a grande diversidade de nossos territórios? Na parte final, apresenta algumas sugestões para a construção de um programa de pesquisa que possa contribuir com a investigação dos territórios e das experiências de desenvolvimento territorial.

Palavras-chave: território, sustentabilidade, políticas públicas

\section{RESEARCH ON TERRITORIAL DEVELOPMENT IN SEMI-ARID}

\begin{abstract}
The article seeks to look further into the discussion on the concept of territory, concentrating on its relationships with local development and sustainable development in northeastern semi-arid. From this perspective, the authors try to answer questions like: What are territories and why must they be privileged as objects of research programmes and public policies? What is the meaning of territorial development and in what way does this concept differ from the concept of local development? How can the reference to a territorial development approach help solve the serious problems of Brazilian society, and also consider the diversity of our territories? In conclusion, some suggestions are presented for the construction of a research programme which could bring contributions for both the conceptual reflection on territories and, at the same time, the practical experiments of territorial development in progress at Brazil.
\end{abstract}

Key words: territory, sustainability, public policies, 


\section{INTRODUÇÃO}

As questões territoriais têm recebido cada vez mais atenção dos meios acadêmicos e sociais, refletindo a crescente e competitiva integração global de lugares e regiões. O governo brasileiro, com a criação da Secretaria de Desenvolvimento Territorial (SDT) no âmbito do Ministério do Desenvolvimento Agrário (MDA), optou pelo enfoque territorial como elemento norteador de políticas públicas, especialmente aquelas voltadas para o desenvolvimento rural e para a agricultura familiar. Instituições governamentais e não governamentais como EMBRAPA e EBRAE têm também anunciado a adesão ao enfoque territorial para orientar suas ações. Em várias regiões do Brasil, as políticas de desenvolvimento territorial, ao lado das políticas sociais de educação e saúde, têm sido apresentadas como a forma privilegiada, para não dizer única, de intervenção do Estado.

Este texto, resultado de uma série de debates com pesquisadores vinculados à Embrapa Semi-árido e ao Grupo de Pesquisa em Agricultura Familiar (GPAF) da UFCG, tem como objetivo contribuir com as reflexões de pesquisadores, professores, estudantes e gestores de políticas públicas envolvidos com a temática do desenvolvimento territorial no semi-árido nordestino.

Estas reflexões são importantes por dois motivos. Em primeiro lugar, porque é preciso investigar o grande número de experiências em andamento - programas e projetos - inspiradas nos pressupostos do desenvolvimento territorial, apreendendo as dinâmicas que engendram e os impactos na melhoria da qualidade de vida das pessoas e no reordenamento dos territórios alvos destas ações. Em segundo lugar, porque é necessário aprofundar, no âmbito das ciências sociais, a própria discussão sobre o conceito de território, suas relações com o desenvolvimento local e a sustentabilidade, permitindo contribuir com o aperfeiçoamento das ações e políticas voltadas para os territórios brasileiros e para a agricultura familiar.

A primeira parte deste artigo focaliza justamente a segunda classe de problemas acima indicados. Tentamos responder a algumas perguntas que nos parecem fundamentais no processo de aprofundar o debate sobre a temática do desenvolvimento territorial entre os cientistas sociais: O que são territórios e por que devem ser privilegiados enquanto orientadores de programas de pesquisa e de políticas públicas? O que significa desenvolvimento territorial e em que este conceito se diferencia da noção de desenvolvimento local? Como a referência a este enfo- que pode ajudar a resolver os graves problemas da sociedade brasileira, especialmente do semi-árido nordestino, considerando, inclusive, a grande diversidade de nossos territórios?

Em seguida, na parte final, apresentamos algumas sugestões para a construção de um programa de pesquisa que possa contribuir com a investigação dos territórios e das experiências de desenvolvimento territorial em andamento no Brasil. Este programa apresenta novas perguntas a serem respondidas e deve influenciar as respostas futuras que poderemos dar às questões acima indicadas.

\section{O QUE É O TERRITÓRIO?}

Milton Santos e Silveira (2001) resumem bem as dificuldades e ambigüidades associadas à noção de território:

A linguagem cotidiana freqüentemente confunde território e espaço. E a palavra extensão, tantas vezes utilizada por geógrafos franceses (étendue), não raro se instala nesse vocabulário, aumentando as ambigüidades. [...] Por território entende-se geralmente a extensão apropriada e usada. Mas o sentido da palavra territorialidade como sinônimo de pertencer aquilo que nos pertence [...] esse sentimento de exclusividade e limite ultrapassa a raça humana e prescinde a existência de Estado. Assim, essa idéia de territorialidade se estende aos próprios animais, como sinônimo de área de vivência e de reprodução. Mas, a territorialidade humana pressupõe também a preocupação com o destino, a construção do futuro, o que, entre os seres vivos, é privilégio do homem.

O território hoje é entendido como “[...] um espaço construído histórica e socialmente, no qual a eficiência das atividades econômicas é intensamente condicionada pelos laços de proximidade e pelo fato de pertencer a esse espaço. O território é, então, um resultado e não um dado". (CIRAD-SAR, apud SABOURIN, 2002). Todo território, portanto, "pertence” a um grupo social. E é, também, produto do entrelaçamento de projetos individuais e coletivos, em que se instituem processos de identificação e de negociação dos interesses comuns e conflitantes.

Dessa forma, o território é algo permeado pela lógica da dominação e dos interesses, muitas vezes conflitantes, inscritos tanto em um espaço físico quanto em sua forma de ocupação. Temos, portanto, uma concepção do território como espaço em que se confrontam diferentes poderes e estratégias de gestão - que poderíamos chamar “território-espaço de poder". 
Dito de outra maneira, os territórios não definem as formas das relações sociais. Falar em território não implica democracia, nem mesmo desenvolvimento. Temos territórios de não-desenvolvimento, territórios de fome e de miséria, com relações arcaicas de dominação marcadas pelo clientelismo. Em vários casos, como na situação específica do semi-árido brasileiro, o problema maior consiste em mudar as relações de poder, inserir os excluídos e fazer com que as populações gerenciem seu próprio destino.

Há, ainda, uma concepção mais operacional de território - que poderíamos chamar de "território-espaço de projeto”, desenvolvida em torno de uma identidade já consolidada ou em processo de consolidação. VITOR ATHAYDE et al. (2003), a partir de um trabalho de identificação, caracterização e classificação de projetos de desenvolvimento territorial na Bahia, parece partir desta concepção mais operacional do conceito ao definir território como o espaço onde se executa um projeto político de desenvolvimento territorial.

Um projeto territorial é essencialmente político, envolvendo atores e instituições locais que não necessariamente defendem os mesmos grupos, interesses e idéias, mas trabalham de forma articulada, buscando consensos em torno de um tipo de desenvolvimento. De modo geral, o projeto territorial é guiado por uma atividade/ação dominante, quase sempre econômica (mas não exclusivamente) e, em torno ou além dela, articula outras atividades que beneficiam mais pessoas e novos ambientes. O territórioespaço de projeto não tem que estar restrito a limites municipais e não se restringe a uma única atividade/ação. Mas qualquer que seja a concepção dominante, territórioespaço de poder ou território-espaço de projeto, não se pode perder de vista a diversidade dos territórios. Eles possuem realidades e potencialidades diferentes, com contextos sociais, políticos, econômicos e culturais que suportam possibilidades de ação dos agentes sociais engajados nas iniciativas que objetivam o desenvolvimento.

\section{COMO CARACTERIZAR OS TERRITÓRIOS DO SEMI-ÁRIDO NORDESTINO?}

Os territórios existem e há uma grande diversidade deles. Como identificá-los? Como caracterizá-los? Como categorizá-los? Outras perguntas de caráter operacional também surgem: Como escolher os territórios para engajar uma ação de desenvolvimento territorial? De fato, é preciso definir critérios na identificação e classificação dos territórios.

Considerando o impacto da globalização, a melhor alternativa seria basear-se em critérios de integração diferenciados. Num trabalho de tese (TONNEAU, 1994), a partir de dados da década de 1980, identificamos três grandes grupos de territórios rurais no Nordeste:

- Espaços em recomposição onde o desaparecimento dos latifúndios permite a instalação de uma agricultura familiar precária, na qual a produção tende a subsistência com pouca penetração no mercado. A dinâmica dos assentamentos de reforma agrária no semi-árido em grande medida corresponde, hoje, a esta lógica;

- Espaços onde a agricultura familiar está consolidada, existindo uma diversificação da demanda agrícola induzida por atividades extrativistas ou por empregos públicos, bem como a produção de um mercado favorecido pela proximidade de uma demanda urbana;

- Os pólos agro-industriais - áreas integradas à economia nacional e internacional, nos quais a presença de infra-estruturas de comunicação e de comercialização é determinante para a competitividade dos produtos. Aqui, as formas de produção capitalistas são dominantes e permitem a competitividade.

Esta situação tem se transformado na última década, radicalizando-se as oposições entre agro-pólos e os territórios “marginalizados”. O Sub Médio do Vale do São Francisco (SMSF) tornou-se um dos maiores pólos de fruticultura irrigada do mundo. Por ano, na região, são produzidas aproximadamente 800 mil toneladas de frutas em uma área estimada em 125 mil hectares, conforme informação da Valexport (Associação dos Produtores e Exportadores do Vale do São Francisco) referente a 2003. As principais frutas responsáveis pelo crescimento da região são a uva e a manga, colocando-a em posição de destaque em relação à produção nacional e internacional, introduzindo o Brasil de forma competitiva no mercado mundial em relação a esse tipo de cultura (BLOCH, 1996; SIQUEIRA, 2003). O Brasil já é conhecido mundialmente como o maior produtor de variedades nobres de manga. O pólo Petrolina-PE/Juazeiro-BA atende, hoje, a boa parte da demanda do mercado internacional por este produto (MANN, 2002). Dados da Valexport indicam que a região respondeu, em 2003, por $95 \%$ da uva e por $90 \%$ da manga exportadas pelo Brasil.

Por outro lado, a produção agropecuária nordestina 
encontra-se em crise. Atingiu o seu auge no fim da década de 1980 e, a partir de então, passa a apresentar índices decrescentes. Segundo o relatório base para a recriação da Sudene - Por uma política de desenvolvimento sustentável para o Nordeste, a crise das atividades do complexo gadoalgodão-lavouras fez com que a contribuição do semi-árido para a economia regional caísse de $28 \%$ em 1970 para $21 \%$ em 2000, fazendo com que a produção per capita passasse de $74,7 \%$ para $53,2 \%$ no mesmo período (Ministério da Integração Nacional, 2003).

Paralelamente, sobretudo a partir da década de 1990, as políticas de infra-estrutura (distribuição de energia, acesso à água, organização dos transportes) e sociais (bolsa-alimentação, renda mínima, educação, saúde, entre outras) possibilitam a melhoria do nível de vida das populações rurais, em que pesem os grandes problemas que ainda precisam ser enfrentados. As políticas sociais, em particular a aposentadoria, limitaram o êxodo rural para os grandes centros, beneficiando, acima de tudo, os supermercados e a agroindústria, transformando os produtores rurais em consumidores. Esse processo tem sido qualificado por alguns autores (GOMES, 20001; VEIGA, 2001) como "economia sem produção".

Percebe-se que, apesar do sucesso econômico, as regiões dos pólos agro-industriais permanecem vulneráveis aos riscos econômicos e climáticos e não conseguiram avançar na solução dos problemas ambientais (poluição, perda da biodiversidade.), de segurança alimentar (qualidade e dependência) e sociais (concentração da renda, reprodução social em grandes extensões de terra sem vida rural). Quadro que tem proporcionado uma série de questionamentos acerca da sustentabilidade desse modelo (JARA, 1998; MORIN, 2002; GORGESCU-ROEGEN, 1979; ALMEIDA et al. 2001).

Tanto nos pólos agroindustriais quanto em outras zonas, a insatisfação em termos do desenvolvimento alcançado é grande. O documento Por uma política de desenvolvimento sustentável para o Nordeste (Ministério da Integração Nacional, 2003) propõe uma estratégia de desenvolvimento regional alicerçada em torno de um compromisso com a inclusão social. O objetivo principal da ação não deve basear-se na busca de taxas de crescimento produtivo (que é um meio e não um fim), mas na geração de oportunidades de inserção social para milhões de nordestinos.

A insatisfação com as políticas e ações de desenvolvimento e com os resultados que geraram leva-nos a refletir sobre que novas políticas públicas são mais adequadas para o desenvolvimento do semi-árido nordestino. Refle- xão que passa, necessariamente, pela busca de inspiração nas realizações da sociedade civil. É, nesta perspectiva, que gostaríamos de introduzir a discussão sobre a pesquisa do desenvolvimento territorial.

\section{O DEBATE EM TORNO DO DESENVOLVIMENTO TERRITORIAL}

A principal justificativa para a utilização do conceito de desenvolvimento territorial, tanto para operacionalizar pesquisas sobre a realidade social quanto como instrumento de intervenção sobre essa realidade, é de que se trata de um processo específico de aproveitamento e produção de capital social, interpretado em termos das possibilidades de ação coletiva que se funda em laços de proximidade, reciprocidade e confiança mútua e que podem ser traduzidas "em crescimento e geração de riquezas” (DUNCAN, 2003). O desenvolvimento territorial aparece fortemente no contexto do debate sobre o desenvolvimento do semi-árido como uma das possibilidades de resposta articulada entre o poder público e a sociedade civil diante dos problemas apontados como causas do subdesenvolvimento.

O quadro da página seguinte aponta outras expectativas relacionadas à aplicação do conceito de desenvolvimento territorial como elemento norteador de políticas públicas.

O dinamismo das experiências de desenvolvimento local colocadas em marcha pela sociedade civil demonstrou, em parte, estas expectativas. Porém, essas iniciativas são ainda restritas, localizadas e, até hoje, não foram traduzidas em ações ao nível das coletividades territoriais. Um dos pontos cruciais na noção de desenvolvimento territorial e, até o momento, ausente nas experiências concretas já vivenciadas, é o entrecruzamento e a interligação entre as iniciativas locais e a ação dos poderes públicos em todas as esferas - nacional, estadual e municipal.

Como destacou Ducan (2003):

O enfoque territorial é uma visão essencialmente integradora de espaços, atores sociais, agentes, mercados e políticas públicas de intervenção. Busca a integração interna dos territórios rurais e destes com o restante da economia nacional, sua revitalização e reestruturação progressiva, assim como a adoção de novas funções e demandas. [...] Portanto, a meta fundamental do desenvolvimento sustentável dos territórios rurais é estimular e favorecer a coesão social e territorial das regiões e dos países onde ela é empregada como elemento harmonizador dos processos de ordenamento (regulação descendente) e de desenvolvimento (reação ascendente) das sociedades nacionais. 
Causas do subdesenvolvimento do semi-árido

O tradicionalismo e a pouca disposição para a mudança

A dominação e a exploração

A ausência de empresários e a falta de gosto pelo investimento

A ausência de dinamismo social

\section{Potencialidades do desenvolvimento territorial}

Favorece a emergência de valores universalistas, baseados no regaste da identidade do território.

Busca reforçar a coesão social, os laços de proximidade e de solidariedade comunitária objetivando ressaltar a eqüidade, o respeito à diversidade, a solidariedade, a justiça social, o sentimento de pertencimento e inclusão.

Favorece a ação dos empresários, no sentido de Shumpeter: portadores de iniciativa.

Aumenta a capacidade de ação da sociedade civil (historicidade) e dos movimentos de base.
Estes dois processos - de ordenamento e de desenvolvimento - fazem referência às ações complementares (o planejamento territorial e a experimentação social) e as articulações entre dois atores principais (representantes do poder público e da sociedade civil organizada). Nesta perspectiva, promover o desenvolvimento territorial é: a) orientar e integrar as ações; b) potencializar a dinâmica social; e c) criar ou aperfeiçoar os arranjos institucionais que facilitem o desenvolvimento.

A “definição do possível" é uma importante etapa de qualquer processo organizado de desenvolvimento e vai orientar e integrar as ações dos diversos atores envolvidos no processo, em relação às potencialidades e aos recursos (físicos e humanos); ao nível do desenvolvimento e da acumulação em capital; às oportunidades do mercado e, também, ao projeto de sociedade, aos rumos e aos objetivos da ação. Normalmente, estas grandes orientações são reunidas em um plano plurianual, que vai servir para orientar os investimentos e, em particular, a infra-estrutura.

Mobilizar os atores, adaptando-se e sendo adaptado por eles, consiste em importante ação para potencializar a dinâmica social, refletida em competências técnicas, administrativas e institucionais.

A construção de novos arranjos institucionais passa pela elaboração de normas e regras que regulem a ação do poder público e de empresários, agricultores familiares e técnicos, definindo um conjunto de deveres, responsabilidades e direitos, bem como pela costura de parcerias entre iniciativa privada, organizações populares (comunidades, sindicatos, associações), instituições de apoio (ONGs) e poderes públicos.

O grande desafio é fazer com que o planejamento seja a expressão das necessidades da população, vivenciadas no presente e projetadas para o "futuro". Enfrentar este de- safio implica em encontrar boas soluções para antigos problemas dos programas de desenvolvimento: aproximar os tomadores de decisão das realidades sociais; garantir a participação das organizações da sociedade civil; dinamizar as administrações municipais carentes de recursos humanos e financeiros; e viabilizar o funcionamento dos conselhos municipais. Em resumo, garantir as práticas da boa governança. O sucesso de um "território" depende da qualidade das inter-relações entre recursos, atividades econômicas, necessidades da população, distribuição de riqueza, ações dos grupos sociais, governança e apoio do Estado e das suas instituições.

Em uma palavra, o projeto de desenvolvimento territorial deve ser coerente. Esta coerência deve se expressar: a) Entre objetivos e recursos existentes (recursos físicos e humanos);

b) Entre as oportunidades econômicas ofertadas pela inserção em territórios mais abrangentes;

c) Entre infra-estrutura e as necessidades do projeto;

d) Entre a ação da sociedade civil e do Estado, num processo de boa governança.

\section{O DESENVOLVIMENTO SUSTENTÁVEL COMO PROJETO PARA OS TERRITÓRIOS?}

Mesmo onipresente nos discursos dos mais diferentes atores sociais, a noção de Desenvolvimento Sustentável ainda é objeto de intenso debate. Nos termos do Relatório Brundtland (1988), é o “desenvolvimento que responde às necessidades do presente sem modificar a capacidade das gerações futuras de responder as suas próprias necessidades”. Geral em sua formulação, mas pouco prática em termos de suas implicações, esta definição famosa 
do conceito omite o fato de que as necessidades humanas são socialmente criadas. Não estamos nos referindo a necessidades naturais, mas historicamente construídas e reflexo das formas das relações entre indivíduos e grupos.

Em termos mais específicos, a noção de desenvolvimento sustentável traduz uma tensão entre objetivos diversos e mesmo contraditórios:

- econômicos, sociais e de proteção ambiental;

- de curto e de longo prazo;

- individuais e coletivos; e

- locais e globais.

A força do conceito reside justamente, acreditamos, na relevância destas contradições, expressando a complexidade das sociedades contemporâneas. Longe da idéia original de equilíbrio, a noção de sustentabilidade convida a refletirmos sobre os meios com os quais poderemos tratar as tensões, os conflitos, as contradições que - da mesma forma que a cooperação, a solidariedade social, a reciprocidade - são elementos constituintes das sociedades humanas.

Se, em muitos momentos do debate, a noção de desenvolvimento sustentável está fortemente associada ao reforço de princípios, a construção de uma nova ética econômica e ambiental - podemos citar, para ficar num único exemplo desta abordagem, Sachs $(1974 ; 1980)$ - ela deve ser percebida, principalmente, pelo caráter revelador de tensões e processos sociais. E é, nesta perspectiva, que pode ser importante elemento do desenvolvimento territorial, entendido como prática social de negociação, planejamento, coordenação e implantação de ações públicas.

A noção de sustentabilidade agrega, ao debate sobre o desenvolvimento dos territórios, a consciência dos diferentes interesses e clareza sobre a complexidade das relações entre seres humanos e natureza e dos elementos envolvidos nos processos de mudança social. Por outro lado, a referência aos territórios, em suas múltiplas interações e práticas sociais, permite um debate mais apropriado da sustentabilidade, em que os princípios são reformulados na ação dos agentes da mudança social.

\section{ENTRAVES AO DESENVOLVIMENTO TERRITORIAL SUSTENTÁVEL}

Há, pelo menos, três grandes entraves à implementação de políticas e programas de desenvolvimento territorial sustentável no semi-árido:

I. No Nordeste e, particularmente, no semi-árido, a agricultura familiar vem se mantendo, nos últimos trinta anos, ao custo de uma pressão crescente sobre os recursos naturais. Isso ocorre, principalmente, devido ao peso do subdesenvolvimento que obriga as populações locais a conviverem com importantes limitações, as quais contribuem diretamente para a degradação dos recursos naturais. Entre estas limitações, podemos citar a pressão fundiária e o pequeno tamanho de grande parte das propriedades; a pobreza e a falta de oportunidade de geração de renda, em mercados pouco dinâmicos; e a manutenção de práticas predatórias de uso do solo e de outros recursos. A transferência de grande parte da produção do algodão do Nordeste para o Mato Grosso foi motivada pelo "bicudo", mas também pelo esgotamento das terras. Mesmo no interior do Nordeste, têm sido verificados novos fluxos migratórios em direção a fronteiras agrícolas, nos cerrados da Bahia e Piauí, provavelmente motivados pelo esgotamento dos solos em áreas de antigas propriedades. Os perímetros irrigados também não têm se demonstrado como alternativas viáveis a longo prazo de aumento da produção agrícola e de introdução de novas práticas agrícolas, a não ser em áreas ou setores muito localizados.

II. No Brasil, as políticas públicas são sempre pensadas em termos setoriais e têm grande dificuldade em beneficiar regiões marginalizadas como é o caso do semiárido nordestino. Retomando o exemplo do sul do Piauí, de maneira caricatural e provocadora, podemos dizer que o Ministério da Agricultura favorece o desmatamento e a expulsão dos posseiros, o Ministério do Meio Ambiente financia o reflorestamento e o Fome Zero garante a alimentação dos posseiros expulsos. Articuladas a políticas públicas, as práticas de desenvolvimento territorial sustentável não estão isentas das burocracias e incapacidades do aparelho estatal brasileiro e, particularmente, dos estados e municípios nordestinos.

III. O gerenciamento e as tomadas de decisão nas várias instituições do Estado ainda são realizadas de forma vertical. Apesar dos discursos sobre a democracia e a participação, as práticas - como constatamos em vários trabalhos (TONNEAU e SIDERSKI, 2004; TONNEAU e BARROS, 2003) - dos técnicos, e mesmo de algumas ONGs, são marcadas ainda por autoritarismo e clientelismo ou, ao contrario, de "admiração irrestrita" para com os agricultores, impedindo uma parceria consistente. $\mathrm{Na}$ relação entre Estado e sociedade civil, entre os dois processos de ordenamento e de desenvolvimento, o peso das decisões do Estado ainda é determinante, sobretudo quan-

Raízes, Campina Grande, Vol. 24, nº 01 e 02, p. 45-53, jan./dez. 2005 
do os movimentos sociais não existem ou são incipientes.

Devido a fatores econômicos (falta de recursos, pobreza, desemprego); sociais (dependência, subordinação); geográficos (isolamento, comunicações, limitantes naturais); educacionais (educação formal deficiente, analfabetismo, baixa informação e capacitação) e práticas políticas (pouca participação, clientelismo), a complexidade das situações de não-desenvolvimento faz com que grande parte dos atores, sobretudo os segmentos sociais que constituem o que se poderia denominar de "sociedade civil não-organizada”, não é contemplada pelas ações formais das políticas públicas. Em algumas regiões, os fatores desagregadores são parcialmente compensados pela forte identidade cultural e pela solidariedade desenvolvidas em práticas religiosas, no trabalho conjunto, no compartilhamento de recursos naturais escassos e no uso comum da terra para criação de animais.

Para ter parceria é preciso parceiros! Ser parceiro, ter as condições de ser parceiro não se improvisa, não se decreta. Há, portanto, a necessidade de um processo de aprendizagem, avaliando como as dinâmicas de desenvolvimento hoje reconhecidas como forte, a exemplo do caso da Articulação para o Semi-Árido, nasceram há menos de 10 anos com atividades limitadas, mas que deram suporte a um processo consistente de aprendizagem. Este processo de aprendizagem foi popularizado pela FAO através da promoção das Escolas de Campo que, como qualquer outro tipo de organização que tenha um cunho técnico ou social, permitiu uma reflexão comum e tornou-se um instrumento de desenvolvimento, na medida em que vai ser o suporte de um processo gerador de conhecimento, de habilidades e de intercâmbio de saberes. Pouco importa a modéstia inicial do tema abordado, o importante é ele ser tratado de maneira sistêmica, tentando integrar os diferentes componentes de um processo de desenvolvimento.

\section{TEMAS DE PESQUISA}

As considerações que nós fizemos, até agora, contribuíram, talvez, para precisar alguns conceitos, mas não conseguiram, ainda, responder as perguntas iniciais: Por que o desenvolvimento territorial? O conceito é operacional? Ou deve ser arquivado no cemitério das idéias perdidas do desenvolvimento? Responder a estas perguntas é, de uma certa maneira, a ambição de vários projetos de pesquisa que estão sendo iniciados. Mas o que pesquisar? Qual objeto de pesquisa?
Um primeiro eixo de pesquisa aparece como ligado ao estudo dos territórios e da suas diversidades. Devemos pensar em zoneamentos baseados na dinâmica dos territórios. O exercício necessita da definição de critérios. Os trabalhos de Athayde (2003) identificam diversos tipos de território: o consolidado, o emergente, o prioritário, o potencial e o não-prioritário, sublinhando, enfim, a importância da qualidade de concepções e de execuções de projetos. Sabourin et al. (2004) usando as teorias das trajetórias de desenvolvimento, utilizam as categorias territórios de colonização, territórios marginalizados, territórios consolidados e diversificados e territórios-bacias de produção. Todos estes trabalhos, de fato, tentam posicionar os territórios em relação a um movimento histórico de integração econômica mais ou menos exitosa. Estas teorias são interessantes na medida que se aproximam daquelas que permitem caracterizar as diferentes formas de agricultura familiar.

O segundo eixo de pesquisa é a caracterização dos projetos dos diferentes atores. De maneira esquemática, dois projetos se afrontam: um projeto transformador e um projeto de convivência. Evidenciam-se, por um lado, uma estratégia que objetiva fortalecer os estabelecimentos familiares através de um processo endógeno de inovações técnicas e organizacionais baseado no conceito de agroecologia (respeito ao meio ambiente e aproveitamento otimizado dos recursos localmente disponíveis) e no de desenvolvimento solidário; e, por outro lado, uma estratégia que busca melhorar a situação econômica e social das famílias rurais mediante um apoio exterior eficiente (assistência técnica, financiamento, formação) com a finalidade de modernizar as técnicas de produção, promover o uso racional dos insumos agrícolas e melhorar o desempenho comercial dos estabelecimentos familiares. Considera-se que a primeira estratégia corresponde a um modelo de agricultura familiar sustentável e solidário enquanto a segunda encontra sua lógica num modelo de agricultura familiar comercial (TONNEAU e DINIZ, 2003).

O terceiro eixo é a caracterização das experiências que fazem sucesso, que tem uma dinâmica de desenvolvimento, pelo menos aparente. O "experimentalismo social” emergiu no Brasil na última década, tendo, como uma de suas grandes características, o processo inovador no campo da inclusão social e da redefinição de espaços, atores e papéis para a promoção do desenvolvimento. Passando por diversas formas e iniciativas da sociedade, chegamos atualmente numa experimentação inovadora 
de um padrão produtivo que, por um lado, coloca a agricultura familiar como sujeito central do processo de desenvolvimento rural e, por outro, leva em consideração os valores culturais e os saberes locais dos agricultores. De maneira geral, foram as organizações não-governamentais (ONGs) que introduziram e difundiram no Brasil esta experimentação social, como uma espécie de "contra modernização" em oposição às formas emergenciais e compensatórias de se pensar o rural. Os resultados desta experimentação social merecem ser analisados e referenciados para além dos discursos redutores, nos quais os resultados desta experimentação podem contribuir na definição de políticas públicas.

O quarto eixo é a analise dos dispositivos de diálogo e de negociação entre os dois grandes atores, o Estado e a sociedade civil. Pois, uma das características do Estado brasileiro, no momento atual, é a busca do governo em criar um novo paradigma de desenvolvimento para o rural a partir desse experimentalismo social. A opção de diálogo e interação estabelece uma forma inovadora na relação entre Estado e sociedade civil, criando, assim, um processo de "experimentalismo institucional". Em muitos dos documentos oficiais está dito que as "[...] análises fundamentadas apontam para um fato: as políticas públicas implementadas nas últimas décadas para promoção do desenvolvimento rural no Brasil ou foram insuficientes, ou não pretendiam mesmo proporcionar melhorias substanciais na qualidade de vida das populações que habitavam o interior brasileiro" (DUNCAN, 2003, p. 04). A decisão de construir uma política nacional que apoiasse o desenvolvimento sustentável dos "territórios" rurais passa pelo reconhecimento da necessidade de uma articulação entre políticas nacionais e iniciativas locais inovadoras.

\section{CONSIDERAÇÕES FINAIS}

É o avanço da pesquisa sistemática sobre as ações do desenvolvimento territorial que permitirá responder as questões que temos formulado neste trabalho. O impacto da decisão do governo federal de integrar suas políticas em torno deste conceito ainda está sendo gerado. E, em muitos sentidos, é ainda cedo para termos respostas fundadas em observação, análise e interpretação.

O conceito de desenvolvimento territorial não é uma panacéia, um remédio milagroso para todos os males do país e, particularmente, do semi-árido. Até o momento, informa práticas promissoras, inovadoras, desafiadoras que, no entanto, confrontam-se com muitos entraves estruturais - sendo, o mais grave deles, a enorme desigualdade que caracteriza nossa sociedade, em seus mais diferentes aspectos.

Nosso fetiche pelo "desenvolvimento" pode, talvez pela primeira vez, no caso das políticas públicas para o semiárido, ser aproveitada em iniciativas que se fundam em práticas sociais localizadas nos territórios. Mas, há o risco de o discurso não conseguir se concretizar em mudanças efetivas nas relações entre poder público e sociedade civil. A dificuldade dos poderes públicos municipais em atuarem como elementos efetivos da gestão dos territórios do semi-árido requer uma reflexão urgente e ações efetivas que garantam maior capacidade de governança no nível local. O projeto do desenvolvimento territorial sustentável, como dito anteriormente, depende de parcerias verdadeiras. Não poderá ser desencadeado unicamente pelo desejo do governo federal.

\section{REFERÊNCIAS BIBLIOGRÁFICAS}

ATHAYDE, V. Uma proposta de identificação, caracterização e classificação de projetos de desenvolvimento territorial. MDA In: TONNEAU, Jean Philippe et al. Desenvolvimento Territorial e Convivência com o Semi-Árido Brasileiro - Experiências de Aprendizagem (Relatório final). Petrolina: Embrapa Semi-Árido, 2003, 46 p.

ALMEIDA, S. G. de, PETERSEN, P; CORDEIRO, Â. Crise socioambiental e conversão ecológica da agricultura brasileira: subsídios à formulação de diretrizes ambientais para o desenvolvimento agrícola. Rio de Janeiro: ASPTA, 2001.

BLOCH. D. As frutas amargas do Velho Chico: irrigação e desenvolvimento no Vale do São Francisco. São Paulo: Livros da Terra: OXFAM, 1996.

COMMISSION MONDIALE SUR LENVIRONNEMENT ET LE DÉVELOPPEMENT, dite Commission Brundtland (1988), Notre avenir à tous. Montréal, Éd. du Fleuve.

DUNCAN, M. O desenvolvimento territorial: o projeto do MDA In: TONNEAU, Jean Philippe et al. Desenvolvimento Territorial e Convivência com o Semi-Árido Brasileiro - 
Experiências de Aprendizagem (Relatório final). Petrolina: Embrapa semi árido, 2003, 46 p.

GOMES, M. G. A economia sem produção do Semi-Árido nordestino. In VELLOSO, João Paulo dos Reis (coord.) Brasil 500 anos: futuro, presente e passado. Rio de Janeiro: J.Olympio, 2000, 544 p

GEORGESCU-ROEGEN, N. Demain la décroissance. Lausanne: Pierre-Marcel Favre, 1979

JARA, C. J. A sustentabilidade do desenvolvimento rural. Sustentabilidade: uma encruzilhada civilizatória. Brasília: IICA, Recife: Seplan, 1999, p. 13-37

MANN, F. A manga brasileira: organização das exportações e desenvolvimento no mercado europeu. São Paulo: ESALQ-CEPEA (Relatório final), 2002.

MORIN, E; KERN, Anne-Brigitte. Terra-Patria. A agonia planetária. Porto Alegre: Sulina, 2002, 184 p.

MINISTÉRIO DA INTEGRAÇÃO NACIONAL. Bases para a Recriação da SUDENE, por uma política de desenvolvimento sustentável para o Nordeste, Secretaria de Políticas de Desenvolvimento Regional/GTI-Grupo de Trabalho Interministerial para a Recriação da SUDENE, julho, Brasília, 2003.

SABOURIN, E. Desenvolvimento rural e abordagem territorial. Conceitos, estratégias e atores. In: SABOURIN, E.; TEIXEIRA, O. A. (Ed.) Planejamento e desenvolvimento dos territórios rurais. Conceitos, controvérsias e experiências. Brasília: Embrapa Informação tecnológica. p. 21-37, 2002.

SABOURIN, E.; CARON, P.; TONNEAU, J. P. Dynamiques territoriales et trajectoires de développement local: retour d'expériences dans le Nordeste brésilien., Français. In: Agricultures, v.13, n. 6, p. 539-545, 2004

SACHS, I. "Environnement et styles de développement", Annales - Économies, Sociétés, Civilisations, n.3, maijuin, p. 553-570, 1974.
Stratégies de l'écodéveloppement. Paris: Éd. ouvrières et Éd. Économie et Humanisme, 1980.

SANTOS, M.; SILVEIRA, M. L. O Brasil - território e sociedade no início de século XXI. São Paulo e Rio de Janeiro: Record, 2001.

SIQUEIRA, T. V. A cultura da manga: desempenho no período 1961/2001. Rio de Janeiro: BNDS Setorial, n. 17. p. 3-68, mar/2003.

TONNEAU J. P.; SIDESKY P. Evento de capacitação: "metodologias participativas de geração de conhecimentos”. Relatório final de execução do contrato. Projeto Dom Helder Camara MDA - Ministério de Desenvolvimento Agrário. 13 p. mais anexos, 2004.

TONNEAU J. P. Modernisation des espaces ruraux et paysannerie: le cas du Nordeste du Brésil. Thèse (Dr. Géographie), Nanterre: Université de Paris, 459 p., 1994

TONNEAU, J. P; BARROS, E. da R. Evaluation du projet "Actions intégrées d'Agriculture, Santé et Education dans l'Etat du Ceara au Nord-est du Brésil", GAAC, ESSOR, Montpellier: Cirad Tera, n 23/2003, 150 p.

TONNEAU J. P, et. al. "Desenvolvimento Territorial e Convivência com o Semi-Árido Brasileiro" - Experiências de Aprendizagem. EMBRAPA, FAO, FAGRO, CIRAD, (Relatório final) e Anais do Seminário. Petrolina: Embrapa Semi-árido, 30 setembro de 2003, 42 p.

TONNEAU J. P.; DINIZ P. O. A multifuncionalidade da agricultura contra a "fome de trabalho"? Elementos do debate no Nordeste do Brasil. In: TEXTOS DO SEMINÁRIO FRANCO BRASILEIRO DE PESQUISA SOBRE MULTIFUNCIONALIDADE DA AGRICULTURA (Séminaire Franco-Brésilien de recherche sur la multifonctionnalité de l'Agriculture), Florianopolis, Brésil, 2003.

VEIGA, J. E. et al. O Brasil rural precisa de uma estratégia de desenvolvimento. Brasília: Convênio FIPE-IICA (MDA/CNDRS/NEAD), 2001. 